\title{
Event evaluation: definitions, concepts and a state of the art review
}

Steve Brown

Finders University of South Australia,

Adelaide, Australia

Donald Getz

University of Calgary, Calgary, Canada, and

Robert Pettersson and Martin Wallstam

Mid Sweden University, Ostersund, Sweden

\begin{abstract}
Purpose - The purpose of this paper is to define event evaluation, develop a conceptual model of its process and elements, review pertinent literature, and draw conclusions pertaining both to the discourse on evaluation and its praxis.

Design/methodology/approach - General review of literature and development of a conceptual model of the evaluation process.

Findings - The review suggests that impact assessments have dominated, but are only one type of evaluation; research and papers on evaluating the worth of events has been minimal, while those on the evaluation of various management and marketing functions is fragmented.

Research limitations/implications - It is concluded that little has been written about evaluation paradigms and systems, although the discourse on sustainability and triple bottom line accountability has led to a greater emphasis on non-economic considerations.

Originality/value - The conceptual model of the evaluation process and its components offers a systematic approach to shaping evaluation discourse and methods. Conclusions are drawn on how to advance evaluation research and methods applied to events.
\end{abstract}

Keywords Methods, Impact assessment, Value, Measures, Evaluation worth, Worth

Paper type General review

\section{Introduction}

The overall purpose of this paper is to examine the meanings, methods, and practice of event evaluation, with the aim of advancing both discourse and praxis. This is undertaken primarily by means of literature review and concept development, leading to conclusions with a suggested research agenda.

Evaluation is, in part, an essential management function of information gathering and feedback through which processes can be improved, goals more effectively attained, and by which organizations can learn and adapt. To "evaluate" is also to place a value on something, or to pass judgment on its quality, effectiveness, or worth. Impact assessment is not the same as evaluation, nor is pure research; evaluation occurs within policy, planning, and decision-making processes and is therefore often political in nature. The impacts most researched, discussed, and used by government agencies and funding authorities are almost exclusively economic in nature - though there has been a recent shift toward the inclusion of socio-cultural impacts and a triple bottom line (TBL) approach - but these are a sub-set of an more comprehensive and holistic approach - that can be collectively described as "event evaluation." 
IJEFM

6,2

Despite recognition of evaluation's vital role in policy making, managerial improvement, and event design, it has been a minor theme in the literature on planned events. Clifton $e t$ al. (2012, p. 89), following an evaluation of festivals in the UK, argued that "in a culture of evidence-based decision making, reliable, and robust evaluation is also essential." Their review concluded that serious weaknesses occurred in the context of evaluating public-policy initiatives related to events: a lack of prioritization, advocacy presented as evaluation, and poor quality reporting; complex and politically sensitive objectives are difficult to objectify, while evaluation itself has been under-resourced or viewed as optional.

In the literature review it is demonstrated that event scholars and practitioners have been preoccupied with economic impact assessment, although the trend is definitely to take a longer-term perspective on the value of events and their legacies within a TBL framework. This concern is now expanding to consider managed portfolios and entire populations of events, which compounds evaluation problems. Progress has been stalled in part by the predominance of economic impact assessments and a lack of theory and methodological advancement in the other outcome domains, and in particular the difficulty of proving cause and effect for intangible social and cultural outcomes. There is also very little guidance available on valuing portfolios, or assessing the dynamics and health of event populations.

Evaluation of organizations, event quality, and event outcomes is a key issue in the planned-events sector. It is of critical importance to ensure success from the multiple perspectives of owners, producers, customers, and other stakeholders. Increasingly, evaluation is tied to certification which is in itself required by many funding agencies and by those granting rights to bid on and produce events. Evaluation is at the heart of sustainability, as without it organizations cannot learn and improve nor can they be held accountable for costs and benefits.

Event evaluation continues to evolve, expand, and become more complex as the discourse on events and event-tourism evolves. The basic applications remain intact, including placing a value on events and their sub-elements through visitor satisfaction or return on investment (ROI) measures. The usual methods remain important, such as visitor satisfaction or economic impact assessment, but event evaluation must now meet much broader objectives including sustainability (in itself a complex matter), encompassing questions of social responsibility, cultural and environmental benefits. The concept of long-term, sustainable legacies now accompanies every mega event and should form part of event portfolio management.

The paper commences with definitions and development of a general model of event evaluation; not a how to model, but a conceptual overview of evaluation paradigms, contexts, purposes, methods, measures, and uses. This model provides the structure for the remaining sections.

\section{Definitions and meanings}

Event evaluation can be defined as the holistic assessment of an event through the utilization of a broad range of measures and approaches to determine its value and impacts in an agreed or prescribed context.

The word "value" is our starting point, and it is used frequently in English as a noun, adjective, verb, and adverb (see Figure 1). Dictionary definitions usually entail synonyms, and for the noun "value" they include worth, utility, advantage, benefit, profit, merit, and usefulness. These synonyms say a great deal about how the value of an event might be determined, but inevitably raise the question "by whom" or "from whose perspective"? 


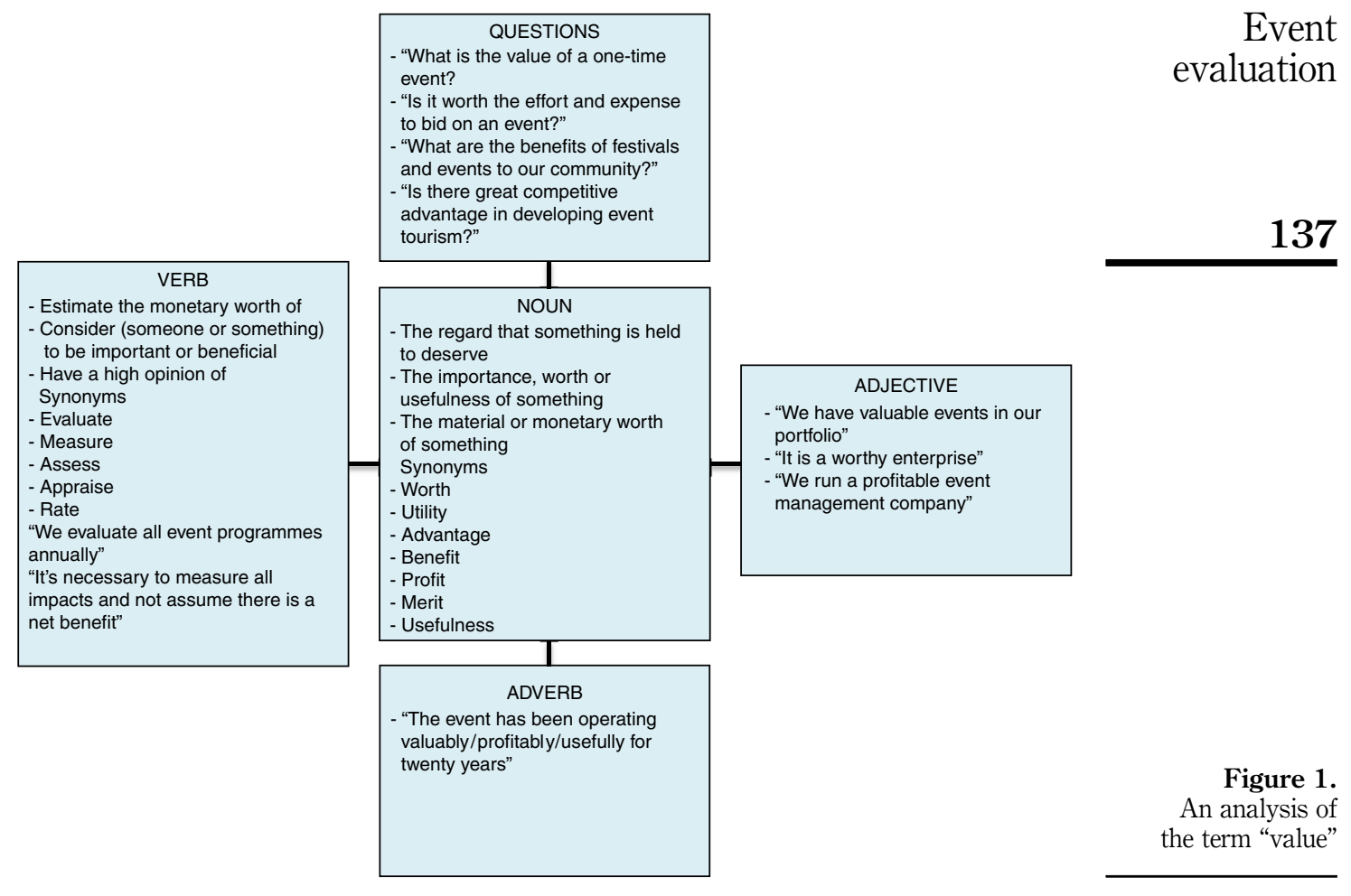

The figure also displays common uses of the verb, which brings "evaluate" into the picture and leads to the necessity for measurement. As an adjective, we can call an event valuable as a business or tourist asset or worthy of public support. In its adverbial form, it is common practice to refer to an event as being operated profitably, usefully, or valuably. The terms "sustainable event" (or events operated "sustainably") have been increasingly applied in an events context. Sustainability implies that an event has merit from a particular point of view or related to a specific set of criteria, and is therefore a confirmation of worth or merit.

At the top of the figure is a set of typical questions that can be asked in any discussion of event evaluation: what is an event's value? Is it worthy of support? Does it generate benefits, and for whom? Does it offer any advantage relative to competitors or over alternative uses of resources? These and similar questions tend to shape the discourse, and evaluators must learn how to answer them.

\section{The meaning and processes of evaluation}

For managers and researchers there are two widely recognized meanings of evaluation: the systematic assessment of the worth or merit of some object, and the systematic acquisition and assessment of information to provide useful feedback about some object (Trochim, 2006).

The literal meaning of evaluation is to assign worth or value, yet many so-called evaluation projects do not do so. Rather, they are technical processes of information gathering and analysis within a planning or decision-making process. Any research on 
IJEFM

6,2

events can provide input to evaluations, although most of it has not been designed to do so. Economic impact assessments can be used for evaluation purposes, but unfortunately often substitute for full evaluations. In themselves they do not provide enough information to determine the worth of an event from more than the one perspective of economic development.

What a given society, agency, or person values at any point in time is open to discussion, debate, and politics; it is not a given. Therefore, we cannot say that there is a perfect or universal set of evaluation questions and targets. Evaluation is not merely a collection of methods, it involves purpose, perspective, and judgment. There is science to evaluation, but also art. What do we want to know, and how will we use that information are vital, initial questions. What methods are appropriate, ethical, and practical? Who will conduct the evaluation and how will they be held accountable? Is the process open and transparent, understandable, and fully utilized to make progress? Many stakeholders have to be involved in this conversation.

Events increasingly have direct mandates to foster urban development, design, renewal, and positioning strategies, all of which impose new considerations on evaluators. Furthermore, acknowledging the spectacular growth of events, their size, cost, and importance around the world, we must now address the evaluation of event populations and managed portfolios of multiple events. Both theory and methodology lag far behind these emerging needs.

\section{Internal and external evaluations of event}

Within a systems approach to event management or event tourism, both internal and external evaluation processes are essential (see Getz, 2012, 2013). Internal evaluation is a standard management function, usually undertaken by senior managers or owners, and often supported by a routine technical process of gathering and analyzing data.

Evaluation is also conducted externally, sometimes as a planned input to event operations and sometimes independently. As events have become legitimized as tools for a wide range of public policies and corporate or industry strategies, many stakeholders are evaluating their investments and interventions in the event sector. This trend has resulted in demands increased accountability to multiple stakeholders and their particular criteria, making the manager's evaluation tasks both complex and politically charged. To fully explore this complexity requires consideration of stakeholder theory and related event-specific research (e.g. Larson and Wikstrom, 2001; Mossberg and Getz, 2006; Crespi-Vallbona and Richards, 2007; Getz et al., 2007; Parent and Seguin, 2007; Andersson and Getz, 2008; Leopkey and Parent, 2009; Larson, 2009; Prebensen, 2010; Ziakis, 2013; Harris, 2014).

Transparency has also become an issue. While many event owners and managers might prefer to conduct their evaluations in secret, or event-tourism development agencies might seek to avoid public scrutiny altogether, it is definitely in the interest of the public and many other stakeholders to insist upon an open and standardized evaluation process. This tendency is most pronounced when government support is critical, as in supporting festivals or bidding on events, because the intervention has to be politically justified.

\section{Professional practice}

The most usual treatment of evaluation is in the context of project and program planning, and in such process models evaluation constitutes the final stage, with 
feedback loops to influence future decisions. Goldblatt (2011, p. 65) explains that this is a dynamic process, should include stakeholder input, and is connected to setting key performance indicators (KPI) for the event. Allen et al. (2011, p. 292) state:

[...] event evaluation is critical to the event management process. It is the final step in the planning process, where the goals and objectives set at the start of an event are used as benchmarks to determine its final outcomes and success.

Allen et al. (2011) also said that the TBL approach is increasingly recognized by governments and researchers alike. Their textbook, Festival and Special Event Management contains a full description of the evaluation process from this perspective, including instructive case studies.

Studies on the evaluation practices of event managers or development agencies have been infrequent, consequently we have an incomplete and perhaps dated picture of the state of art in praxis. Carlsen et al. (2000) surveyed the literature on evaluation and impact assessment and reported on a Delphi survey of event experts in Australia which revealed the most important perceived pre- and post-event evaluation topics and measures. While a standardized approach was desired, that aim has never been achieved.

Wood (2009, p. 175 citing Pugh and Wood, 2004 and Thomas and Wood, 2003) concluded from UK studies that festivals were marked by:

[...] ill-thought out objectives, which are then assessed, leaving evaluation to the basics of attendance counts, questionable economic impact measures, and assessment of the functional aspects of the event [...] In the UK [...] many departments did not undertake any type of evaluation and those that did focused on attendance figures, participant feedback, and attendee satisfaction.

O'Sullivan et al. (2009) reviewed event evaluations by local governments in Wales and concluded that most had focussed on improving processes and measuring economic impacts; social-cultural objectives were common, but these outcomes were not usually evaluated.

Williams and Bowdin (2007) reviewed event evaluation literature and studied seven UK arts festivals as to their evaluation purposes, methods, and uses. They concluded that evaluation was well understood in terms of its roles in measuring event success related to goals, shaping the planning process, meeting stakeholder expectations, and making improvements. The methods, data, and objects of the arts festivals' evaluations were summarized, noting that the audience in particular was of extreme importance, as well as financial performance, media coverage, artists and other stakeholders.

Robertson et al. (2009) found that 47 of 56 festival directors from a UK sample did a formal evaluation of their event, of which 77 percent measured community involvement or community satisfaction levels; 60 percent said they gained feedback from sponsors and 53 percent undertook an economic impact evaluation. Interestingly, they discovered that older festivals were less likely to evaluate community involvement or satisfaction or performer satisfaction.

Sherwood's Australian doctoral research (cited in Sherwood et al., 2005) scrutinized 85 assessments of events conducted by government agencies and found that mostly economic impacts were covered. Environmental impacts were scarcely evaluated, and social-cultural impact assessment was slowly developing. The state of art at that time was summed up as a lack of TBL comprehensiveness and a failure to integrate methods.

Toolkits that offer advice, methods and examples on event evaluation and impact assessment have been developed in a number of settings. The Cooperative Research 
IJEFM

6,2

Centre in Sustainable Tourism in Australia (now defunct) published a series on event impacts including the book Economic Evaluation of Special Events: A Practitioner's Guide, by Jago and Dwyer (2006). The ENCORE toolkit produced and modified by Cooperative Research Centre researchers in its final version adopted a TBL approach including appropriate resident and stakeholder surveys.

A consortium of UK sponsors has created a web site full of impact assessment advice and examples called eventIMPACTS (UK Sport, 2008). Its contents cover attendance, economic, social, environmental, and media impacts. Presumably cultural impacts are covered under "social" but there is a gap here, as well as weaknesses in the media and environmental sections that reflect slow progress theoretically and methodologically in the event evaluation field.

\section{Evaluation in professional standards (Event Management Body of Knowledge (EMBOK), Meeting and Business Event Competency Standards (MBECS), ISO)}

The EMBOK did not explicitly recognize or discuss evaluation. Presumably it is a skill or technique needed to realize the core values and perform the main management functions, as implied in this quote from Silvers et al. (2005, p. 194): "The core values of creativity, strategic thinking, continuous improvement, ethics, and integration are the values that must permeate all decisions throughout event management regarding every element, phase, and process."

Within MBECS, evaluation is an integral part of both strategic and project management (Meeting Professionals International (MPI), 2012). For example, under "strategic planning" the following actions are specified:

(1) manage strategic plan for meeting or event (develop mission, goals, objectives: determine feasibility, determine requirements to carry out meeting/event, develop financial summary, monitor strategic plan);

(2) develop sustainability plan for meeting or event (implement plan, demonstrate environmental responsibility); and

(3) measure value of meetings and business events (develop evaluation plan, measure ROI, evaluate/audit, evaluate effectiveness of risk management plan).

Elsewhere more specific monitoring and evaluation actions are specified, such as "evaluate staff."

The event sustainability management system codified in the ISO 20121 standard (International Organisation of Standardization (ISO), 2012) embeds evaluation but does not specify what the goals or measures of sustainability should be. The document explains it this way:

The standard does not specify which sustainability issues to manage or what performance levels to achieve. What the standard requires is that an organisation has in place a transparent process through which it systematically evaluates the issues relevant to its operations and sets its own objectives and targets for improvement.

This represents a view of sustainability as a process and not a set of outcomes, clearly articulated in this statement:

In a nutshell, sustainability is about how an organisation continues to run its activities in a commercially successful way whilst contributing towards a stronger and more just society and reducing its impact on the environment. To achieve ISO 20121, an organisation will need to demonstrate that it has considered within its management system all key financial, economic, social and environmental issues relevant to its operations; focusing solely on environmental issues will not be sufficient. 
In other words, it is the evaluation system, encompassing goals, objectives, measures, and reporting that is of primary importance. Each event will presumably pursue a somewhat different path. This highlights that there is a significant gap in existing event evaluation research and methods and that an industry-agreed model of the event evaluation process is an essential next step.

\section{A model of the evaluation process}

Figure 2 is a conceptual framework that can be used as a starting point in any discussion of event evaluation. The framework incorporates evaluation contexts, paradigms, functions, measures as well as discussion of what needs to be evaluated and why.

\section{Evaluation paradigms}

According to Rossi et al. (2004) the positivist paradigm dominates, with its emphasis on determining cause and effect through experimental designs and on quantitative measurement. Applied to the events sector it is reflected in the prevailing emphasis on forecasting and measuring demand and economic impacts, customer satisfaction and the link to loyalty or expenditure, effectiveness in achieving goals, and efficiency in resource acquisition and deployment. As this paradigm incorporates the view that evaluation is science, there is a need for theory development so that evaluators can confidently predict outcomes and explain divergence from goals, but this is notably lacking with regard to events.

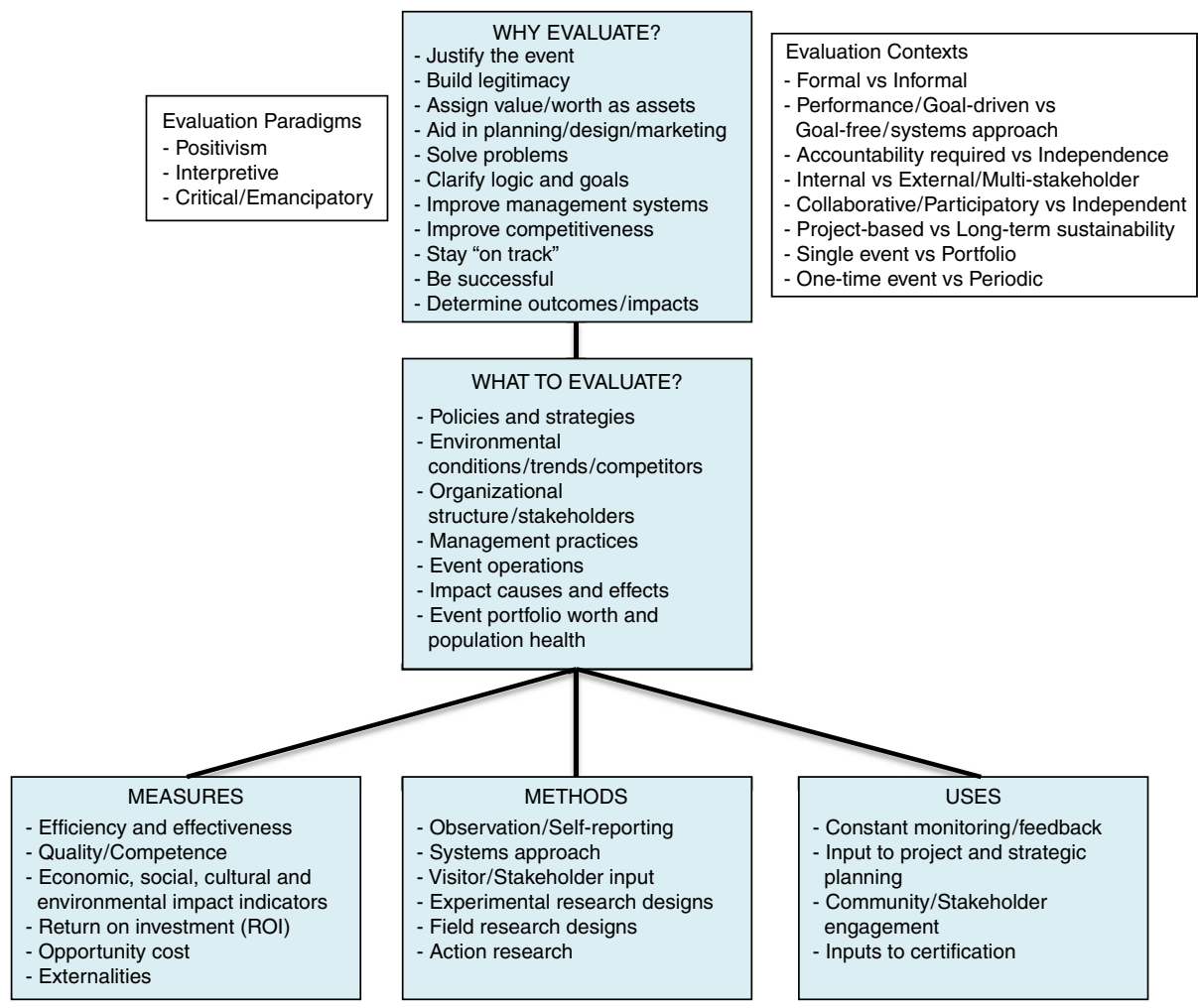

Figure 2.

A model of the evaluation process 
IJEFM

6,2

142

A set of interpretive approaches have been described by Potter (2006). These have in common an attempt to work with stakeholders to understand their expectations, experiences, and meanings before making judgment about value or worth. Close links with stakeholders and the community at large will obviously facilitate interpretive event evaluation using specific qualitative methods including focus groups, interviews, and observation. This paradigm is likely to be more appropriate in evaluating event populations, policies, and legacies, all of which are open to various interpretations of cumulative impacts and values. Wood (2009, p. 183) put forward a framework for the evaluation of festival impacts that can be considered interpretive in design. It was:

$[\ldots]$ intended to incorporate a wider view of evaluation than has been used so far in event evaluation. It suggests that the views of all stakeholders are considered, that evaluation takes place within specific and unique contexts (and therefore cannot be standardized), a wide range of methods and sources of information is required to give a full and balanced view, that outcomes or objectives although important are not the only aspects to evaluated, and that a cost-benefit analysis or economic evaluation is not suitable for this type of festival where many of the effects are intangible, social, and long term.

A third paradigm is that of critical-emancipatory evaluation (Potter, 2006) which is usually based on action research. The aim is to make changes, or initiate transformative processes, such as to employ events in community capacity building through institutional networking, or to facilitate healthy lifestyles and participation in the arts or sport. Where the aim is to empower citizens or groups the process can be quite political and controversial, especially if existing power structures are challenged. A less political application might consist of action research to create a new hallmark event with long-term tourism and community benefits (e.g. as described by Andersson et al., 2013), although any action-research process can become politically charged.

\section{Emerging sustainability paradigm}

The events sector has certainly been adopting sustainability principles and practices, although it is unclear if this is a completely new paradigm or an amalgam of the others. The discourse on event sustainability contains elements of positivism (e.g. green practices save money and can improve event brands), interpretivism (e.g. a concern for multi-stakeholder perceptions of benefits), and the critical (e.g. demonstrating how events and event venue decisions reflect the power of elite groups). To many event managers sustainability is equated with survival, not specifically the environment or community (Ensor et al., 2011).

Hall (2012) discussed sustainability in the context of mega events, with reference to three "frames of sustainability" namely: economic sustainability, balanced sustainability, and steady-state sustainability. He argued:

Only steady-state sustainability is regarded as sufficient to maintain or enhance natural capital. However, the likelihood of the required policy learning to occur for this paradigm to be adopted are slim given the role of political and corporate interests in promoting mega-events as a solution to problems of place competitiveness rather than as a symptom of the problems of contemporary neoliberal thinking with respect to events, places, and sustainability.

A wide range of concepts and methodologies can be relevant to sustainability, including: "green" or "sustainable event" standards (Jones, 2010; ISO, 2012), "corporate social responsibility" (Bradish and Cronin, 2009; Laing and Frost, 2010), "social license to operate" (Ponsford and Williams, 2010), "TBL” (Raybould et al., 2005; Sherwood, 2007; 
Hede, 2007), event, carbon and ecological "footprints" (Collins et al., 2009; Andersson and Lundberg, 2013), "use and non-use values" (Andersson et al., 2012), "social leveraging” (Chalip, 2006; O’Brien and Chalip', 2008), and, “social utility” (Schulenkorf, 2009). Whatever event managers do, sustainability will also be linked to environmental influences, which brings "organizational ecology" into the equation. As argued by Getz et al. (2013a, b), there will generally be threats to the viability of events from competition for resources, support and audiences.

The institutionalization of a new paradigm is a process requiring many steps and possible setbacks, and for events Getz (2009) argued that it requires full application of TBL thinking - a set of goals and measures were advocated covering the social, cultural, ecological, and economic dimensions of event outcomes. Whatever the definition of sustainability, this emerging paradigm has profound implications for evaluation of the "worth" of events and justifications for investment and intervention in the events sector. At a minimum, events and event-development agencies must now demonstrate value in a multi-stakeholder context, and take a longer-term perspective on outcomes and legacy. As the paradigm gains acceptance at the political, corporate, and event operational levels, it will also lead to growing attention to long-term, cumulative impacts, resolution of stakeholder conflicts, the meaning and management of a "healthy" portfolio and population of events, and the synergistic effects arising from many actors pursuing event-related strategies and programs.

\section{Why evaluate?}

As illustrated in the diagram, the most common purposes are to assign value or worth, to aid in improving management and performance, and to determine outcomes - all of which can be important in justifying an event or building legitimacy.

Surprisingly little attention has been paid to the question of assigning overall value or worth to a planned event, let alone to portfolios and populations of events. In the for-profit sector, events are a business and the need to make profit is a given, so events have clear asset value in this context. In the not-for-profit sector events are usually conceived as providing a necessary or worthwhile service to the community or a specific group, and therefore some measure of value such as attendance, or of legitimacy - such as political and other stakeholder support - is essential to their continuance. It is in the public sector, where events are produced or receive support from government, that a specific justification for intervention is necessary. All too often that justification is limited to purported tourism and economic benefits, whereas the dramatic rise in exploiting events as instruments of diverse policy purposes demands much broader justifications.

The management-oriented purposes of event evaluation are much clearer and are widely implemented:

- to aid in planning/design/marketing, solve problems, clarify logic, and goals;

- to improve management systems; and

- to improve competitiveness, stay on track, be successful.

Outcome or impact assessment is part of this process, especially employing measures of quality, customer satisfaction and loyalty, and some calculation of ROI is often desired. Both efficiency of resource acquisition and use, and effectiveness in goal attainment are commonly examined.

Alkin and Christie's (2004) review of evaluation literature generated a model that outlines the different schools and tendencies within the field. They concluded that 
IJEFM

6,2

144 evaluation theory is the result of two parallel driving forces. One is manifested in social inquiry, or "evaluation as research." It follows a scientific rationale where the desire to understand the dynamics of individuals and groups in different social contexts has been the principal motivating factor. In short, social inquiry has supplied us with the methods used in program and organizational (read "event") evaluation. The other strand of evaluation discourse has been focussed on the need for accountability in management processes. It assumes an instrumental perspective in its view of evaluation. Actions taken and resources used in the frame of commercial or public programs should be monitored to ensure effectiveness and identify potential areas of improvement. Those accountable are thereby provided information on their performance relative to goals, processes, and outcomes.

\section{Evaluation function}

When evaluating something or someone, one needs to first establish the function of said evaluation. By function we mean the intended purpose of evaluating something, both in terms of the information sought as well as the final use of this information. Expected outcomes and measurement criteria are a product of the function (Taras, 2005).

Scriven (1967) was the first author to clearly distinguish between the different functions of evaluation. In his seminal paper on evaluation methodology, he identifies what has become the widely adopted categories of "formative" and "summative" evaluation. Formative evaluation is that which helps the user get ready for summative judgment; filling organizational gaps, and aligning organizational processes. Regarding events, the following can be considered to have formative evaluation functions: needs assessments, market demand and feasibility studies, stakeholder input, benchmarking, or comparative studies. Logically, the results of all research and outcome assessments aid in the re-formulation of plans and designs.

Although common in leisure programming or provision of facilities, evaluation of needs has been absent in the events sector. This presumably reflects a dominant bias that conceptualizes events as either business, in which case the emphasis has been placed on destination and venue selection - or as the unnecessary luxury of entertainment and event-related tourism. Re-conceptualizing events in a service context, say as part of leisure or health services, would have major implications for evaluators and theorists.

Summative evaluation simply holds up the outcomes/impacts of a program against qualifying criteria of merit (COM) or worth. Economic impact assessments, measures of stakeholder and customer satisfaction, financial audits, and media content analysis are examples of great importance to events. As soon as merit or worth are raised as points of discussion, the political, and multi-stakeholder nature of event evaluation becomes unavoidable.

Taras (2005) argued that both are part of the broader process of assessment and that at least formative evaluation is dependent on its summative counterpart for its existence. That is, for a formative evaluation to take place, summative criteria, and objectives must be determined from which to work from.

Another functional category, "developmental" evaluation (Gamble, 2008), has been added in an effort to account for longitudinal evaluation as opposed to the more cross-sectional methods often represented by its formative and summative kin. Developmental evaluation also incorporates aspects of complexity theory and social change. It requires a certain level of innovative drive and a predisposition to risk-taking in the culture of the user organization (Table I). 


\begin{tabular}{|c|c|c|}
\hline Evaluation function & Situation & \\
\hline $\begin{array}{l}\text { Summative } \\
\text { evaluation }\end{array}$ & $\begin{array}{l}\text { At the end of a program or initiative when key decisions about its future are } \\
\text { going to be made } \\
\text { When judging a model's merit or worth for continuation, expansion or other } \\
\text { major decisions }\end{array}$ & \\
\hline $\begin{array}{l}\text { Formative } \\
\text { evaluation }\end{array}$ & $\begin{array}{l}\text { When fine-tuning a model } \\
\text { When a future summative evaluation is expected and baseline data will likely }\end{array}$ & 145 \\
\hline $\begin{array}{l}\text { Developmental } \\
\text { evaluation }\end{array}$ & $\begin{array}{l}\text { be needed } \\
\text { When working in situations of high complexity. When working on early stage } \\
\text { social innovation }\end{array}$ & \\
\hline \multicolumn{2}{|c|}{ Source: Adapted from Gamble (2008) } & evaluation fu \\
\hline
\end{tabular}

Akin to monitoring, "process evaluation" occurs during the operation of an event or program with the function of keeping it on track to achieve its goals and solving problems that might arise. Various observation techniques and checklists can be used by staff or volunteers, as well as immediate feedback obtained from customers and other stakeholders such as suppliers. Management by "walking around" is an essential tool learned by every event producer, as some issues require immediate attention. For longer events the retention of independent auditors might be a wise investment, covering on-site matters, media coverage, and various external stakeholders as they formulate impressions or identify problems from their perspectives.

\section{Evaluation contexts}

Context often determines what type of evaluation is needed, whether it is performed at all, and how it is conducted. The first consideration can be a matter of formality vs informality, with other considerations listed as follows:

- formal vs informal;

- performance and goal-driven vs goal-free/systems approach;

- accountability required vs independence;

- internal vs external and multi-stakeholder;

- collaborative, participatory vs independent;

- project-based vs long-term sustainability;

- $\quad$ single event vs portfolio; and

- one-time event vs periodic.

Textbooks often incorporate evaluation into planning and programming models, and in relation to events this often means project planning, especially for one-time events. In this context the evaluation will likely be formal and goal driven. Performance objectives or KPI generally accompany this approach. Informal evaluation occurs when people get together to discuss issues, plan for improvements or solve problems without having done research or installed an evaluation system.

There is a danger in goal-driven evaluations that an overly narrow approach will be taken and various unexpected outcomes and externalities will consequently be ignored. This is a frequent criticism of events judged on narrow grounds such as profitability, 
IJEFM

6,2

146

tourist attractiveness, or economic impact estimates. Goal-free evaluation is an option, but likely to be implemented only when there is a need for a completely objective evaluation of processes and impacts (usually conducted by outsiders) that might reveal more than a goal-driven process. Increasing demands for accountability and transparency lead to more comprehensive evaluations and therefore begin to address these risks.

Success for projects - especially in the private sector - is quite different from longterm sustainability. When a project is completed according to specifications, within the budget and on schedule, and stakeholders sign off on it, that is success. One-time events are now expected to generate a positive, long-term legacy that also needs to be evaluated. Periodic events might have a planned life-cycle (therefore, they are intended to be produced only a few times) while others seek permanence or sustainability. Permanence means forever, as valued traditions and institutions (see Andersson and Getz, 2008; Getz and Andersson, 2008), whereas to be sustainable has come to mean compliance with a set of standards or expectations which continuously change.

While it is wise for all organizations to evaluate in order to learn and adapt, sometimes it is done primarily to satisfy demands for accountability. This requirement usually accompanies monetary grants and formal sponsorship contracts. External stakeholders might conduct their own evaluations, such as for determining their ROI in sponsoring an event. Managers might prefer to conduct an evaluation themselves, to ensure control, but having outside experts do it can increase objectivity and perhaps comprehensiveness. If there are internal problems regarding policy or strategy it might be best to employ outside evaluators.

Typical internal evaluations, conducted by and for management, can range from very specific goal-attainment exercises, such as monitoring customer satisfaction, to broad, ongoing evaluations of efficiency, and effectiveness across all management functions. They need not involve stakeholders and might never be reported outside the organization. Some events are very independent and inward-looking, so that their entire evaluation universe consists of ways to improve and sustain the event. The event, in this context, exists for its own sake and might not be conceived as an instrument of any external policy or strategy. Nevertheless, internal evaluation cannot ignore environmental influences, especially those affecting resource acquisition.

External evaluations are conducted from the perspective of stakeholders who evaluate the event and its organization, and are conducted either by outside agents or by event managers who are held accountable for resources and support received. Sponsors and grant givers often insist upon full evaluations or at least impact assessments, and many will conduct their own ROI-type evaluations of events they support; these are not necessarily made public. However, one can argue that adopting principles of social responsibility leads to a greater external orientation, as does increasing institutionalization of an event or the event-producing organization, thereby suggesting the need for transparent evaluations and full, public disclosure. The concept of a social license to operate can be applied, in which case the event is seen to require ongoing community or key-stakeholder support.

Events are increasingly instruments of various industry strategies (both tourism and corporate marketing) and public-policy domains (from economic and urban development to place marketing and civic re-positioning). Accordingly, many largescale, public events are in reality transforming processes designed (or widely expected) to achieve goals that lie outside an event's ability to control. This places a significant burden on events, and requires a completely different approach to evaluation - one that involves a partnership between events and stakeholders, otherwise the task is too large 
and complex. For example, if festivals are expected to foster social integration in a divided community, and not simply provide entertainment, then a significant burden also arises in demonstrating cause and effect.

Evaluation of portfolios of events will be much more complex, starting with numerous environmental forces and stakeholders shaping the portfolio, reflecting an overriding concern for long-term and cumulative impacts, and leading to diverse perspectives on value as demonstrated through multiple evaluations and a wide variety of methods. Longitudinal, meta-analysis of a number of evaluation and impact studies might be required to gain the entire picture:

- What is the property or portfolio worth in economic and subjective terms? Place an economic value through the application of various ROI and asset life-cycle accounting procedures; subjective judgments made through comparisons, discourse, stakeholder input.

- Is our event or portfolio/population of events healthy and sustainable? Use a variety of indicators to monitor cumulative impacts; measure population changes such as births and deaths.

Event evaluations are rare, if non-existent, in the context of the interpretive or criticalemancipatory paradigms, or event as part of action research. This remains a frontier in event studies, in need of both theoretical and methodological advances. Criticism of mega events in particular has been growing, and the conflict over vast expenditures on sports events and facilities that benefit mostly powerful elites in society requires new approaches to evaluation of costs, benefits, and overall worth.

Evaluation of events often has to consider long-term, indirect, often subtle impacts. The term "legacy" applies to all that is left over from the event (or events) as a positive inheritance for future generations, or as costs and problems. For discussions of event "legacies" see Hall (1994), Andersson et al. (1999), Ritchie (2000), Preuss (2007), Quinn (2010), and Sadd (2010). One can ask if an event itself is sustainable, or if its legacy fits into a sustainable development framework.

\section{Measures}

There is always a measurement problem in science, starting with the rubrics that something does not exist unless we can measure it, and everything is affected by the measurement process! In other words, we absolutely need measures for all kinds of impacts, so that unless we have measures of the cultural impacts of events we cannot say if they exist or not. Second, by using a particular measure, such as "growth in arts participation" as a measure of festival success, evaluators can either deliberately or inadvertently shape future design and consequential attendee experiences. That happens (hypothetically) because managers will be held accountable for arts participation increases in their performance evaluations and they will therefore tend to alter the program to ensure that the desired effect occurs.

Measurement is often complex, employing monetary values plus indicators of tangibles and intangibles, so the use of composites or summaries is common. These include cost-benefit ratios and ROI. How these are constructed is important, because stakeholders might easily get a false impression from summaries. Dwyer et al. (2010) provide advice on costs and benefits in tourism and events impact assessments, and Phillips et al. (2008) thoroughly cover ROI approaches and measurement for the events sector.

Impacts are but one category of outcome to measure, and impact assessment does not in itself constitute evaluation. How measures are decided upon and used in assigning 
IJEFM

6,2

148 value or worth are key evaluation issues. In TBL approaches it is crucial is to incorporate externalities into evaluations, as well as consideration of social equity and justice. If the distribution of costs and benefits is not measured, for example, it cannot truly be said that a policy, strategy, or event is worthwhile. This is why so many impact forecasts and assessments focus only on purported tourism-generated benefits: it is either too difficult to be comprehensive; or, the proponents do not want to draw attention to potential costs and negative impacts.

\section{Indicators and checklists}

Rather than starting from scratch every time an evaluation is to be conducted, checklists can be developed to guide the process and ensure that the outcomes match expectations. Checklists, according to Stufflebeam (2001, p. 71) perform these functions:

An evaluation checklist is a list for guiding an enterprise to success (formative orientation) and/or judging its merit and worth (summative orientation). Sound checklists can have profound evaluative applications. Familiar examples are evaluations of behavior against moral codes like the Ten Commandments; evaluations of legal matters against the US Bill of Rights and the other constitutional provisions; [...] evaluations of hospitals and colleges against accreditation criteria; [...] Such checklists can provide valuable assistance to evaluators, their clients, and other stakeholders as they plan, conduct, and judge evaluations.

Scriven (2007) described the typological landscape of checklists as including the enumerating "laundry list" of things to, sequential checklists of processes, and diagnostic, iterative and "COM" formats. COM checklists are the foundation for situations demanding scoring procedures. Their development is a highly stringent process as they need to be inclusive of every possible indicator relevant to a given evaluation context. If not, the subject of an evaluation might appear unjustly strong or weak in a dimension that has not been fully represented by the appropriate criteria.

What is to be measured depends almost entirely on the purpose of the evaluation. In broad terms, the following types of indicators can be relevant to event evaluation and impact assessment:

- Inputs. The resources needed to become successful, competitive, or sustainable, including human, information, financial, natural;

- Processes. The management systems designed to utilize resources efficiently and to be effective in attaining goals; some of these indicators might be useful in monitoring trends or in predicting outcomes; and

- Outcomes. Measures of performance and impacts, taking into account those that can be controlled as well as externalities, financial ratios are typical in business settings, a TBL approach or balanced scorecard is advised for events.

Torres-Delgado and Saarinen (2014) reviewed the literature on sustainable tourism indicators and formulated a list of conditions that define good indicators, most of which are relevant to planned events (see Table II).

What is the starting point for developing indicators? Many have been proposed, including those specific to sustainable events. But they do not necessarily meet all needs and purposes. Bell and Morse (2003, p. 47) proposed four methods for establishing indicators and these approaches can be adapted to the events sector. The first is to base them on historical trends, assuming that a sustainable or successful state prevailed in the past. In this way, indicators would tend to replicate past conditions, and that is not 
Relevance

Scientific precision

Measurability

Transparency

Adaptability

Comparability

Updating

Cost efficiency well

balanced

Territorial

representation

Temporal representation

Sensitivity

Communication

Participation
Relevant to the research program

Scientifically well founded

Containing the necessary and reliable data to proceed to its calculation

Clear as regards its methodology and the selection of parameters

Adaptable to specific characteristics of the territory

Producing comparable results

Using updated data

Efforts expended in data collection well balanced with information

ultimately obtained

Possibility of mapping using georeferenced data

normally something to be desired. A second starting point is to compare events or portfolios of events, as in benchmarking against those considered to be the best. Like all such exercises, it begs the question of determining what caused the success of others.

A theoretical approach could be taken, and this is certainly to be recommended insofar as experts claim to understand what makes for a successful or sustainable event. A careful review of the literature supports establishment of basic principles, both for pursuing success in a competitive environment or a service environment, and for working toward higher levels of sustainability. But this does not by itself ensure relevance or utilization, as many organizers will distrust theory-based exercises. Finally, and most realistically, various stakeholders can be consulted to ensure relevance - but they might have to be educated on the purpose and process.

Getting consensus on any method or set of measures will be difficult, but is most likely to occur at the level of single events or organizations where the context and purpose is fully understood by internal and select external stakeholders. At a wider level, say a city, association, or country, a consensus-building process might take a considerable investment in education, time, and money with no guarantee of success.

\section{Outcome and sustainability indicators}

Undertaking full cost-benefit evaluations or detailed economic impact assessments can be difficult and expensive, with incomparability of methods being a common problem. It is natural, therefore, that evaluators and policy makers will seek a simpler, more standardized approach, and this is increasingly leading to the development of indicators. While comparable, quantifiable indicators are the norm in for-profit businesses, any comprehensive, or TBL approach is immediately faced with the incommensurability problem. This leads evaluators to either place surrogate monetary values on a variety of intangibles, or to opt for a mix if qualitative and quantitative measures.

Whitford et al. (2014, p. 392) developed a set of indicators for evaluating event governance performance. Governance in this context is more than ownership and decision making, it applies to the full interaction of policy actors in which power and authority are shared. Principles for selecting indicators were articulated, including relevance, reliability, completeness, clarity, timeliness, verifiability, and diversity. Indicators are linked explicitly to goals and require suitable data sources and measurement. For example, when the goal is transparent decision making, one indicator could be "the public is informed about the process of resource allocation." Data sources could include public surveys or media analysis. 
IJEFM

6,2

The Global Reporting Initiative (GRI, 2000-2012) developed a supplementary set of indicators for events. The GRI approach is heavy on process, encouraging comprehensive, ISO-type planning and reporting. It suggests what should be measured, rather than setting targets, and in this way treats sustainability as an ongoing process of setting targets for achievement or avoidance/amelioration. For example, under the main heading "economic" events are to measure direct and indirect value creation including that value attributable to sustainability initiatives. Under "environmental," events are to measure waste and energy consumption, but it is up to the organizers to decide what is reasonable. The other main indicator headings are "society," "labor practices and decent work," "human rights," "product responsibility," "sourcing," and "legacy."

Indicators can be grouped into sets, such as "indicators of sustainable events/ tourism" or "indicators of successful/enduring events," each representing a broad purpose. Within these sets individual indicators can be weighted as more important than others, or sub-sets such as economic being less important than social, and then composite indices calculated. Weights and measures will certainly change over time, so there is a need for constant monitoring and adaptability. This is particularly true for both success and sustainability indicator sets, as both must be kept fresh in light of policy, environmental, and competitive changes.

\section{Methods and evaluation systems}

Any research method can be useful, as the determination of appropriate evaluation methods must follow from purpose and context. No doubt visitor surveys are a predominant research tool in evaluating everything from satisfaction to economic impacts, whereas financial and energy audits are not really research methods but provide valuable inputs.

To become a formal and strategically important element in any event or event-related organization, evaluation should not be a series of data collection exercises (which could be viewed as monitoring progress) or one-off reports. Rather, a permanent system is required. An evaluation system will consist of a set of methods, measures and procedures intended for event organizers or others to use in comprehensive evaluation including management functions and impacts.

A systems approach to event management or event-tourism approach is a logical framework within which appropriate and necessary methods can be determined. The model requires consideration of various levels of environment and therefore potentially numerous stakeholders, of inputs including resources and information of value, of management processes and their interdependencies, and of outcomes related to both internal processes and externalities. With the event conceived as a transforming process, the systematic evaluator will automatically take a more comprehensive and open-minded view of what evaluation is to achieve and how it is to be conducted. Both internal and external evaluations are an integral part of this approach.

Pasanen et al. (2009) described the development of a Finnish event evaluation tool called FEET which combined social/cultural, environmental, and economic dimensions. In an effort to be comprehensive, the pilot project included development of questionnaires for event organizers, event visitors (both locals and tourists), local entrepreneurs, local residents, and policy makers.

At Mid-Sweden University the comprehensive Event Compass system has been tested on several events, with results yet to be reported. It is based on a goal-attainment approach in which evaluators measure progress toward specific targets along eight dimensions covering outcomes (economic, social/cultural, and environmental) as well as 
management functions (organization, design, risk, planning, marketing). In the initial baseline evaluation events are able to compare their current goals and evaluation against a set of KPI developed by experts.

\section{TBL and the incommensurability problem}

Elkington (1999) conceived the TBL as a way to add social and environmental costs and benefits to typical corporate accounting. Three separate accounts would be created, named people, profit, and planet. This philosophy is in keeping with sustainable development and corporate social responsibility principles, and has led to repeated calls for a more comprehensive approach to event impact assessment and evaluation. However, the problem of measurement remains, as financial analysis is not easily compared with intangible costs and benefits. Incommensurability (therefore, employing different units of measurement) is also of theoretical concern, in the sense that available theories pertaining to economic impacts are more developed than those pertaining to cultural and social outcomes so that we might have greater certainty about cause and effect.

Raybould et al. (2005) proposed a framework for TBL event impact assessment, based on a set of measureable indicators for each of social, environmental, and economic impacts. While absolute scores on each would be calculated, changes over time would also be measured and compared by reference to fixed or moving averages on all indicators. For a visual summary, results would be displayed on a "synthesis diagram" (therefore, the readily available "radar graph") with the three dimensions scaled 1 to 10; more dimensions could be added if refinements were desired, such as adding destination image:

To draw the chart, scores for each of the components are plotted along the relevant axis, and these points are joined by straight lines creating a geometric shape [...]. The triple bottom line impact of the event can then be expressed by the ratio between the area of plotted triangle and the area of the theoretical maximum defined by the outer limits of the diagram (Raybould et al., 2005, p. 10).

The authors acknowledged that a fixed average would become obsolete over time. As well, it might be necessary to "weight" the three dimensions to reflect different values.

Hede (2007) discovered that of 14 stakeholder groups she canvassed, only three (governments, residents, and community groups) demonstrated interests across all three dimensions of the TBL. Hede concluded that a comprehensive impact evaluation approach had to be introduced at the planning state of an event, and stakeholders had to be convinced of its merit. She further opined that perhaps all three elements of the TBL are not equally important for all events and that a weighted approach might be necessary to take into account, for example, small community festivals that are primarily oriented to fostering community integration.

Andersson and Lundberg (2013) have attempted to deal with TBL incommensurability by employing monetary values for the following: use values (therefore, measured by the direct expenditure of all visitors, minus opportunity costs), socio-cultural value (therefore, willingness to pay, or a consumer-surplus calculation from which perceived disruption allowance is deducted), and environmental costs calculated through both ecological footprint and $\mathrm{CO}_{2}$-equivalent calculations. This approach provides an overall monetary value for an event.

\section{Summary and conclusions}

The definition and various meanings of value and evaluation have been examined, both in theory and related to the practice of event management and event-tourism development. As commonly interpreted and practiced, evaluation is a management process intended to 
IJEFM

6,2

152

improve efficiency and the attainment of goals. Increasingly, however, the very worth of events and event portfolios has come into question, and demands for transparency and accountability have put pressure on event proponents and organizers to improve their evaluation process and procedures. It was argued that impact assessments are not evaluations of worth, as they only reflect one perspective on desired or acceptable outcomes. Full evaluation of costs and benefits is the ideal, one that is seldom attempted, leaving evaluators to seek comprehensive but practical methods and measures that can be used in a valid, standard approach.

Research on event evaluation praxis has been inconsistent, so researchers do not have a complete, current understanding of how thoroughly it is being conducted, where the gaps are, and in particular how effective evaluation is in shaping strategy, policy or operations. Limited evidence suggests that some events and some agencies have institutionalized comprehensive evaluation systems, but that is probably not standard practice in the field. A discussion of sustainability has been necessary, as the movement toward greener and more sustainable events, and event-tourism development, means that standards are being applied and certification systems implemented. Sustainability implies taking a comprehensive or TBL approach in setting goals and evaluating performance. However, because success and sustainability are never assured, only a continuous process of goal setting, evaluation and constant improvement will work and, because many stakeholders are involved, multiple inputs are necessary.

A conceptual model of the entire event evaluation process has provided the main framework for this paper. The starting point is consideration of evaluation paradigms, and it is suggested that most event-related evaluations are positivistic both in the quantitative measures they employ and the assumption that are made about discovering the truth through scientific or quasi-scientific methodology. In this context the greatest challenge for event evaluators is to establish cause and effect. Researchers must generate and test theory to enable prediction of the effectiveness of management practices and design, and to help ensure that events generate the desired benefits within acceptable cost parameters. Many evaluation applications do not, however, require theory. Some are conducted in an interpretive or even critical manner, introducing political, and ideological considerations to establishing the worth of events and the nature of their development and outcomes.

Considerable attention was given to methods and measures for evaluation. While any research method or auditing procedure can provide necessary data for evaluation, some methods and measures are in widespread use and will likely always remain important. These will certainly vary according to the size and type of event, its context and particularly its purposes, so a variety of instruments and measures are needed in the available toolkits. Working toward a standard approach and a set of common indicators that everyone can use will, therefore become increasingly important.

The conceptual model of the evaluation process is not at all the same as an event evaluation system that can be institutionalized by an event organization. Such a system would implement the logic of sustainability and TBL thinking in a way that facilitates strategic planning. It must include internal and external evaluations and impact assessments which consider all costs and benefits. While there are several toolkits available to guide evaluators, the two cited examples of FEET from Finland, and the Event Compass from Sweden come closest to meeting these criteria.

\section{Advancing event evaluation}

There are certain biases or misconceptions that have to be rectified. First, impact assessments are not in themselves evaluations. They can form one part of a comprehensive 
evaluation process but they address only a very narrow range of possible impacts. The typical economic impact assessment is directed toward proving that tourists were attracted, additional income earned by the destination, and other trade, or business leveraging goals were met.

A major shift is needed from the current fixation on evaluating management practices and impacts toward a fuller discourse and related methods for establishing the value or worth of single events, event portfolios, and event populations. This entails justifying private investment or public-sector intervention and will therefore be political in nature. Only a multi-stakeholder approach to valuation or establishment of worth will be politically acceptable within democracies.

Given the emphasis on "greening" and "sustainable events," evaluators must address a broader issue. It is a laudable goal to meet standards like ISO, but this form of praxis does not ensure sustainable events. It is one thing to say an event is "green" or "sustainable" and quite another to say that an event is viable, a success, competitive, has become a permanent institution, or is in some way worthwhile of public or stakeholder support. To be a "sustainable event" or to develop "sustainable event tourism" is to meet a specific set of criteria reflecting a balanced set of social, cultural, economic, and environmental goals that will have to be agreed upon in an open forum. Both "success" and "sustainability" are best viewed as processes, not outcomes or the meeting of fixed standards, and in this context evaluation is designed to guide the process of becoming more successful and more sustainable. A goal-attainment approach will work best.

Evaluators and other stakeholders will benefit greatly if a standard approach can be followed. When all events and agencies follow the same process and use the same measures and methods, comparability becomes possible. This not only makes forecasting more accurate but it also facilitates benchmarking of best practices. As well, the implementation of codes of practice or certification systems depends upon all events following the same guidelines, at least for a minimal level of compliance. In general, politicians and the public want a more transparent and credible approach to the justification of involvement in the events sector, and this means moving well beyond the current emphasis on predicting economic benefits.

Finally, progress is needed in developing theory that can explain and predict the outcomes of various event planning, development, marketing, design, and operational practices. Without theory, evaluation, or management and impact assessment will remain weak, while determination of the worth of events and event tourism will be restricted.

\section{References}

Alkin, M.C. and Christie, C.A. (2004), "An evaluation theory tree", in Alkin, M.C. (Ed.), Evaluation Roots: Tracing Theorists' Views and Influences, Sage, Thousand Oaks, CA, pp. 12-65.

Allen, J., O’Toole, W., Harris, R. and McDonnell, I. (2011), Festival and Special Event Management, 5th ed., Wiley, Brisbane.

Andersson, T. and Getz, D. (2008), "Stakeholder management strategies of festivals", Journal of Convention and Event Tourism, Vol. 9 No. 3, pp. 199-220.

Andersson, T. and Lundberg, E. (2013), "Commensurability and sustainability: triple impact assessments of a tourism event”, Tourism Management, Vol. 37, August, pp. 99-109. 
IJEFM

6,2

Andersson, T., Armbrecht, J. and Lundberg, E. (2012), "Estimating use and non-use values of a music festival”, Scandinavian Journal of Hospitality and Tourism, Vol. 12 No. 3, pp. 215-231.

Andersson, T., Getz, D. and Mykletun, R. (2013), "Sustainable festival populations: an application of organizational ecology", Tourism Analysis, Vol. 18 No. 6, pp. 621-634.

Andersson, T., Persson, C., Sahlberg, B. and Strom, L.-I. (1999), The Impact of Mega Events, Eurpean Tourism Research Institute, Östersund.

Bell, S. and Morse, S. (2003), Measuring Sustainability: Learning from Doing, Earthscan Publications, London.

Bradish, C.L. and Cronin, J.J. (2009), "Special issue: 'corporate social responsibility in sport'”, Journal of Sport Management, Vol. 23 No. 6, pp. 691-794.

Carlsen, J., Getz, D. and Soutar, G. (2000), "Event evaluation”, Event Management, Vol. 6 No. 4, pp. $247-257$.

Chalip, L. (2006), “Towards social leverage of sport events”, Journal of Sport \& Tourism, Vol. 11 No. 2, pp. 109-127.

Clifton, N., O'Sullivan, D. and Pickernell, D. (2012), "Capacity building and the contribution of public festivals: evaluating 'Cardiff 2005'”, Event Management, Vol. 16 No. 1, pp. 77-91.

Collins, A., Jones, C. and Munday, M. (2009), “Assessing the environmental impacts of mega sporting events: two options?”, Tourism Management, Vol. 30 No. 6, pp. 828-837.

Crespi-Vallbona, M. and Richards, G. (2007), "The meaning of cultural festivals: stakeholder perspectives in Catalunya”, International Journal of Cultural Policy, Vol. 13 No. 2, pp. 103-122.

Dwyer, L., Forsyth, P. and Dwyer, W. (2010), Tourism Economics and Policy, Channel View, Bristol.

Elkington, J. (1999), Cannibals with Forks: The Triple Bottom Line of 21st Century Business, Capstone Publishing Limited, West Sussex.

Ensor, J., Robertson, M. and Ali-Knight, J. (2011), "Eliciting the dynamics of leading a sustainable event: key informant responses”, Event Management, Vol. 15 No. 4, pp. 315-327.

Gamble, J. (2008), A Developmental Evaluation Primer, JW McConnell Family Foundation, Canada.

Getz, D. (2009), "Policy for sustainable and responsible festivals and events: institutionalization of a new paradigm”, Journal of Policy Research in Tourism, Leisure and Events, Vol. 1 No. 1, pp. 61-78.

Getz, D. (2012), Event Studies: Theory, Research and Policy for Planned Events, 2nd ed., Routledge, Oxford.

Getz, D. (2013), Event Tourism: Concepts, International Case Studies, and Research, Cognizant, New York, NY.

Getz, D. and Andersson, T. (2008), "Sustainable festivals: on becoming an institution”, Event Management, Vol. 12 No. 1, pp. 1-17.

Getz, D., Andersson, T. and Larson, M. (2007), "Festival stakeholder roles: concepts and case studies”, Event Management, Vol. 10 No. 2, pp. 103-122.

Getz, D., Andersson, T. and Mykletun, R. (2013a), "Sustainable festivals: an organizational ecology approach", Tourism Analysis, Vol. 18 Nos 3/4.

Getz, D., Svensson, B., Pettersson, R. and Gunnerval, A. (2013b), "Hallmark events: definition and planning process", International Journal of Event Management Research, Vol. 7 Nos 1/2, pp. 47-67.

Global Reporting Initiative (GRI) (2000-2012), "Sustainability reporting guidelines \& event organizers sector supplement, version 3.1/EOSS final version”, Global Reporting Institute, Boston, MA, available at: www.globalreporting.org/resourcelibrary/G3-1-English-EventOrganizers-Sector-Supplement.pdf (accessed March 15, 2015). 
Goldblatt, J.J. (2011), Special Events, 6th ed., Wiley, New York, NY.

Hall, C.M. (1994), "Mega-events and their legacies", in Murphy, P. (Ed.), Quality Management in Urban Tourism: Balancing Business and Environment Conference Proceedings, University evaluation of Victoria, Victoria, pp. 109-123.

Hall, C.M. (2012), "Sustainable mega-events: beyond the myth of balanced approaches to mega-event sustainability", Event Management, Vol. 16 No. 2, pp. 119-131.

Harris, R. (2014), "The role of large-scale sporting events in host community education for sustainable development: an exploratory case study of the Sydney 2000 Olympic Games", Event Management, Vol. 18 No. 3, pp. 207-230.

Hede, A.-M. (2007), "Managing special events in the new era of the triple bottom line", Event Management, Vol. 11 Nos 1/2, pp. 13-22.

International Organization for Standardization (2012), "The event sustainability management system", available at: www.iso.org/iso/iso20121 (accessed March 15, 2015).

Jago, L.K. and Dwyer, L. (2006), Economic Evaluation of Special Events, Common Ground Publishing, Altona.

Jones, M. (2010), Sustainable Event Management: A Practical Guide, Earthscan, London.

Laing, J. and Frost, W. (2010), "How green was my festival: exploring challenges and opportunities associated with staging green events", International Journal of Hospitality Management, Vol. 29 No. 2, pp. 261-267.

Larson, M. (2009), "Joint event production in the jungle, the park, and the garden: metaphors of event networks", Tourism Management, Vol. 30 No. 3, pp. 393-399.

Larson, M. and Wikstrom, E. (2001), "Organising events: managing conflict and consensus in a political market square”, Event Management, Vol. 7 No. 1, pp. 51-65.

Leopkey, B. and Parent, M. (2009), "Risk management strategies by stakeholders in Canadian major sporting events", Event Management, Vol. 13 No. 3, pp. 153-170.

Meeting Professionals International (MPI) (2012), "Meeting and business event competency standards", available at: www.mpiweb.org/Portal/MBECS (accessed March 15, 2015).

Mossberg, L. and Getz, D. (2006), "Stakeholder influences on the ownership and management of festival brands", Scandinavian Journal of Hospitality and Tourism, Vol. 6 No. 4, pp. 308-326.

O'Brien, D. and Chalip, L. (2008), "Sport events and strategic leveraging: pushing toward the triple bottom line", in Woodside, A.G. and Martin, D. (Eds), Tourism Management: Analysis, Behavior, and Strategy, CAB International, Cambridge, MA, pp. 319-338.

O'Sullivan, D., Pickernell, D. and Senyard, J. (2009), "Public sector evaluation of festivals and special events", Journal of Policy Research in Tourism, Leisure and Events, Vol. 1 No. 1, pp. 19-36.

Parent, M. and Seguin, B. (2007), "Factors that led to the drowning of a world championship organizing committee: a stakeholder approach", European Sport Management Quarterly, Vol. 7 No. 2, pp. 187-212.

Pasanen, K., Taskinen, H. and Mikkonen, J. (2009), "Impacts of cultural events in Eastern Finland - development of a Finnish event evaluation tool", Scandinavian Journal of Hospitality and Tourism, Vol. 9 Nos 2/3, pp. 112-129.

Phillips, J., Breining, M. and Phillips, P. (2008), Return on Investment in Meetings and Events, Elsevier, Oxford.

Ponsford, I.F. and Williams, P.W. (2010), "Crafting a social license to operate: a case study of Vancouver 2010's Cypress Olympic venue”, Event Management, Vol. 14 No. 1, pp. 17-36. 
IJEFM

6,2

Potter, C. (2006), "Program evaluation”, in Terre Blanche, M., Durrheim, K. and Painter, D. (Eds), Research in Practice: Applied Methods for the Social Sciences, 2nd ed., UCT Press, Cape Town, pp. 410-428.

Prebensen, N. (2010), "Value creation through stakeholder participation: a case study of an event in the high north", Event Management, Vol. 14 No. 1, pp. 37-52.

Preuss, H. (2007), "The conceptualisation and measurement of mega sport event legacies”, Journal of Sport and Tourism, Vol. 12 Nos 3/4, pp. 207-228.

Pugh, C. and Wood, E.H. (2004), "The strategic use of events within local government: a study of London borough councils", Event Management, Vol. 9 No. 1, pp. 61-71.

Quinn, B. (2010), "The European capital culture initiative and cultural legacy: an analysis of the cultural sector in the aftermath of Cork 2005", Event Management, Vol. 13 No. 4, pp. 249-264.

Raybould, R., Fredline, E., Jago, L. and Deery, M. (2005), “Triple bottom line event evaluation: a proposed framework for holistic event evaluation”, Paper Presented at the Event Management Research Conference, July 13-14, 2005, Australian Centre for Event Management, Sydney and Lindfield.

Ritchie, J.R.B. (2000), "Turning 16 days into 16 years through Olympic legacies", Event Management, Vol. 6 No. 2, pp. 155-165.

Robertson, M., Rogers, P. and Leask, A. (2009), "Progressing socio-cultural impact evaluation for festivals", Journal of Policy Research in Tourism, Leisure and Events, Vol. 1 No. 2, pp. 156-169.

Rossi, P., Freeman, H. and Lipsey, M. (2004), Evaluation. A Systematic Approach, 7th ed., Sage, Thousand Oaks, CA.

Sadd, D. (2010), "What is event-led regeneration? Are we confusing terminology or will London 2012 be the first games to truly benefit the existing population?", Event Management, Vol. 13 No. 4, pp. 265-275.

Schulenkorf, N. (2009), "An ex ante framework for the strategic study of social utility of sport events", Tourism and Hospitality Research, Vol. 9 No. 2, pp. 120e-131e.

Scriven, M. (1967), “The methodology of evaluation”, in Tyler, R., Gagné, R. and Scriven, M. (Eds), Perspectives of Curriculum Evaluation (AERA Monograp Series Curriculum Evaluation, No. 1), Rand McNally, Chicago, IL, pp. 39-83.

Scriven, M. (2007), The Logic and Methodology of Checklists, Western Michigan University, Kalamazoo, available at: www.wmich.edu/evalctr/archive_checklists/papers/logic\&methodology_dec07. pdf (accessed December 10, 2013).

Sherwood, P. (2007), "A triple bottom line evaluation of the impact of special events: the development of indicators", $\mathrm{PhD}$ thesis, Victoria University, Melbourne.

Sherwood, P., Jago, L. and Deery, M. (2005), "Triple bottom line evaluation of special events: does the rhetoric reflect reporting?", in Tremblay, P. and Boyle, A. (Eds), CAUTHE 2005: Sharing Tourism Knowledge, Charles Darwin University, Springs, NT, pp. 632-645, available at: http://search.informit.com.au/documentSummary;dn=799890118101493; res $=$ IELBUS (accessed June 24, 2015).

Silvers, J., Bowdin, G., O’Toole, W. and Nelson, K. (2005), "Towards an international event management body of knowledge (EMBOK)", Event Management, Vol. 9 No. 4, pp. 185-198.

Stufflebeam, D.L. (2001), "Evaluation checklists: practical tools for guiding and judging evaluations", American Journal of Evaluation, Vol. 22 No. 1, pp. 71-79.

Taras, M. (2005), “Assessment - summative and formative - some theoretical reflections", British Journal of Educational Studies, Vol. 53 No. 4, pp. 466-478. 
Thomas, R. and Wood, E. (2003), "Event based tourism: a survey of local authority strategies in the UK", Local Governance, Vol. 29 No. 2, pp. 127-136.

Torres-Delgado, A. and Saarinen, J. (2014), "Using indicators to assess sustainable tourism Event
evaluation development: a review", Tourism Geographies, Vol. 16 No. 1, pp. 31-47.

Trochim, W. (2006), "Research Methods Knowledge Base, Web center for Social Research Methods", available at: www.socialresearchmethods.net/kb/ (accessed June 24, 2015).

UK Sport (2008), "eventIMPACTS”, available at: www.eventimpacts.com/ (accessed March 31, 2015).

Whitford, M., Phi, G. and Dredge, D. (2014), "Principles to practice: indicators for measuring event governance performance", Event Management, Vol. 18 No. 3, pp. 387-403.

Williams, M. and Bowdin, G.A.J. (2007), "Festival evaluation: an exploration of seven UK arts festivals”, Managing Leisure, Vol. 12 No. 2, pp. 187-203.

Wood, E. (2009), "An impact evaluation framework: local government community festivals", Event Management, Vol. 12 Nos 3/4, pp. 171-185.

Ziakis, V. (2013), Event Portfolio Planning and Management: A Holistic Approach, Routledge, Oxford.

\section{Corresponding author}

Associate Professor Steve Brown can be contacted at: steve.brown@flinders.edu.au

For instructions on how to order reprints of this article, please visit our website: 